\title{
Case Report \\ Deep Vein Thrombosis and Pulmonary Embolism in the Setting of Mycoplasma Infection
}

\author{
Sandal Saleem (iD) ${ }^{1}$ and Brian Berman ${ }^{2}$ \\ ${ }^{1}$ Department of Pediatric Emergency Medicine, Beaumont Health Royal Oak, 3601 W. 13 Mile Rd., Royal Oak, MI 48073, USA \\ ${ }^{2}$ Oakland University William Beaumont School of Medicine, 586 Pioneer Dr Ste 428, Rochester, MI 48309, USA \\ Correspondence should be addressed to Sandal Saleem; sandal.saleem@beaumont.org
}

Received 24 July 2020; Revised 26 August 2020; Accepted 1 September 2020; Published 6 September 2020

Academic Editor: Michael S. Firstenberg

Copyright (C) 2020 Sandal Saleem and Brian Berman. This is an open access article distributed under the Creative Commons Attribution License, which permits unrestricted use, distribution, and reproduction in any medium, provided the original work is properly cited.

\begin{abstract}
Thirteen-year-old female twins presented one week apart with documented Mycoplasma pneumoniae respiratory infection. Each developed venous thrombosis and pulmonary emboli in association with transient self-limited para-infectious anti-phospholipid antibodies. Comprehensive evaluation revealed no identifiable genetic prothrombotic variables. Both children recovered after receiving antibiotics and anticoagulation therapy. Thrombotic complications associated with Mycoplasma pneumoniae infections are rare, particularly in children; the occurrence of this complication in identical twins has not been previously reported.
\end{abstract}

\section{Introduction}

Mycoplasma pneumoniae is a common pathogen causing community-acquired pneumonia in children $[1,2]$. Extra pulmonary manifestations such as hematologic, neurologic, and mucocutaneous complications associated with Mycoplasma are well recognized. Thromboembolic events in association with mycoplasma have been reported. An analysis published in 2016 cited 9 pediatric cases of Mycoplasma-associated thromboembolic event [3]. All of these patients had anti-phospholipid antibodies [4]. We report identical twins with Mycoplasma pneumoniae infection complicated by pulmonary emboli in association with anti-phospholipid antibodies.

\section{Case Reports}

2.1. Patient 1. A 13-year-old Caucasian female presented with cough and fever of 1-week duration. Chest X-ray revealed left lower lobe segmental pneumonia. The patient was admitted to the hospital after she failed to improve. Intravenous ceftriaxone was added to azithromycin. Blood culture was negative, and sputum culture grew normal flora. Initial laboratory tests showed the following: hemoglobin of 12.2 $(12-15 \mathrm{~g} / \mathrm{dl})$, white blood cell count of 4.5 (4.3-13.5 thous/ $\mu \mathrm{l})$, and platelet count of 236 (150-500 thous/ $\mu \mathrm{l})$. Mycoplasma pneumoniae PCR was positive followed by elevated specific Ig $\mathrm{M}$ being $4.10(<0.9)$ and IgG being $0.88(<0.9)$. On day 3 of hospital admission, she developed increasing respiratory distress. Antibiotics coverage was broadened. Chest CT with contrast showed multifocal pneumonia with bilateral parapneumonic effusions. The patient ultimately required BiPAP for respiratory support and was transferred to the pediatric intensive care unit (PICU).

On day 2 of admission to the pediatric intensive care unit, she complained of left calf pain with mild swelling. US doppler revealed deep vein thrombosis (DVT) in left gastrocnemius, posterior tibial (left), and popliteal and peroneal veins, and chest CT was reread as showing filling defects involving segmental branches to the right middle lobe pulmonary artery and right lower lobe segmental pulmonary arteries. She was started on enoxaparin at a dose of subcutaneous $60 \mathrm{mg}$ ( $1 \mathrm{mg} / \mathrm{kg} /$ dose) twice daily. Echocardiogram was significant for elevated right ventricle (RV) systolic pressure. Anti-phospholipid antibody studies demonstrated an elevated anticardiolipin IgG of 86 (0-14.9 GPL), IgM of 120.7 (0-12.4 MPL), normal IgA of $<9.5$ (0-11.9 APL), and anti-beta-2-glycoprotein IgG/IgM of $<9.5 / 21.9 \quad(<9.5 /$ 21.9 GGU/SMU). DRVVT was elevated to 54 with a 
normalized ratio of 1.3. On PICU day 4, antifactor Xa level was subtherapeutic and enoxaparin dose was adjusted to $70 \mathrm{mg}$ after which the therapeutic level of antifactor Xa of $0.7 \mathrm{U} / \mathrm{ml}(0.6-1 \mathrm{U} / \mathrm{ml})$ was achieved. On PICU day 5, based on her clinical improvement, antibiotics were weaned. She continued to improve and was discharged after 9 days.

At follow-up, her enoxaparin was switched to single daily dose $(120 \mathrm{mg})$ to achieve a therapeutic level of $1.3 \mathrm{U} / \mathrm{ml}(1-$ $2 \mathrm{U} / \mathrm{ml}$ ) for a duration of 3 months. Symptoms completely resolved, and she returned to normal and full activities.

2.2. Patient 2. The 13-year-old Caucasian identical twin of the patient cited above presented to the emergency department with cough of 9-day duration and left leg pain of 2-day duration. She was seen a week prior by her primary care doctor who started azithromycin. Two days later, she was noted to be hypoxic ( $89 \%$ on room air), tachycardiac (131 bpm), and febrile $\left(38.4^{\circ} \mathrm{C}\right)$ in the emergency department. Lung exam showed diminished breath sound on the left, and left calf tenderness was noted. Initial laboratory tests showed the following: hemoglobin of $11.9 \mathrm{~g} / \mathrm{dl}(12-15 \mathrm{~g} / \mathrm{dl})$, white blood cell count of 9.6 thous $/ \mu \mathrm{l}(4.3-13.5$ thous $/ \mu \mathrm{l})$, platelet count of 259 thous $/ \mu \mathrm{l}$ (150-500 thous/ $\mu \mathrm{l})$, lactate of $1.2 \mathrm{mmol} / \mathrm{l}(0.5-2.2 \mathrm{mmol} / \mathrm{l})$, and $\mathrm{BNP}$ of $<10 \mathrm{pg} / \mathrm{ml}(0-100 \mathrm{pg} / \mathrm{ml})$. Mycoplasma pneumoniae PCR was negative followed by elevated specific IgM and IgG levels of $4.39(<0.9)$ and $2.74(<0.9)$, respectively. Echocardiography was unremarkable. Anti-nuclear antibodies were normal. Anti-phospholipid antibody studies demonstrated anticardiolipin IgG of 13.7 (0-14.9 GPL), IgM of 28.8 (0-12.4 MPL), normal IgA of $<9.5$ (0-11.9 APL), and anti-beta2 glycoprotein $\operatorname{IgG/IgM~}<9.5 /<9.5 \quad(<9.5 / 21.9$ GGU/SMU). DRVVT was elevated to $54 \mathrm{sec}(0-41 \mathrm{sec})$ with a normalized ratio of 1.3. A chest X-ray revealed right perihilar interstitial infiltrates. Antibiotic coverage was broadened. Doppler ultrasound for deep vein thrombosis of the lower extremity showed normal venous flow dynamics. CT angiography demonstrated multiple bilateral pulmonary emboli in segmental distribution of bilateral upper lobes, right middle lobe, and left lower lobe, along with dense consolidation of the right lower lobe. She was admitted to the PICU where she was started on an intravenous heparin drip.

On day 2 of hospital admission, she was switched to enoxaparin $60 \mathrm{mg}$ twice daily $(1 \mathrm{mg} / \mathrm{kg} / \mathrm{dose})$. Initial antifactor Xa level was subtherapeutic. Dose was adjusted to $80 \mathrm{mg}$ twice daily, and a therapeutic level of antifactor Xa of $0.7 \mathrm{U} / \mathrm{ml}(0.6-1 \mathrm{U} / \mathrm{ml})$ was achieved. She demonstrated gradual improvement and was discharged home on day 6.

At follow-up, she was switched to single daily dose of enoxaparin $(120 \mathrm{mg})$ with a therapeutic antifactor Xa level of $1.5 \mathrm{U} / \mathrm{ml}(1-2 \mathrm{U} / \mathrm{ml})$ for a duration of 3 months. She had complete resolution of symptoms and returned to normal and full activities.

\section{Discussion}

There are acquired and inherited factors leading to a hypercoagulable state [5]. Acquired factors that promote coagulation pathways include surgery, pregnancy, hormonal replacement therapy, estrogen containing oral contraceptive, malignancy, inflammation, infection, and heparin-induced thrombocytopenia. Genetic factors such as factor $\mathrm{V}$ Leiden and prothrombin G2021 A mutation are identified in a variable percentage of patients depending on demographics.

Mycoplasma pneumoniae-associated hypercoagulable state has been described to be secondary to endothelial damage leading to release of proinflammatory cytokines and activation of procoagulant pathways $[2,3]$. Pulmonary emboli are the third leading cause of mortality associated with mycoplasma infection if not diagnosed and treated promptly [3].

Anti-phospholipid antibodies are found to be elevated in $1-5 \%$ of the healthy population [6]. They can also be elevated in bacterial infection, viral infections, and autoimmune diseases (i.e., lupus) [6, 7]. Elevated anti-phospholipid antibodies have also been reported after immunization $[8,9]$. The mechanism by which thrombosis is precipitated in patients with anti-phospholipid antibodies remains unclear.

Most patients with infectious causes of elevated aPL antibody return to normal levels within 2 or 3 months [10]. Thromboembolic events in association with elevated aPL in the setting of infection are difficult to differentiate from other causes. For both patients, prothrombotic and genetic laboratory evaluations were initiated after enoxaparin was discontinued to identify potential genetic prothrombotic variables in these identical twins. Laboratory studies revealed resolution of elevated anti-phospholipid antibodies (anticardiolipin IgA, IgG, IgM, beta-2-glycoprotein 1 IgG and IgM, and DRVVT). The genetic evaluation was normal for factor $\mathrm{V}$ Leiden, prothrombin gene mutation, fibrinogen, thrombin time, factor VIII, protein C activity, protein S activity, plasminogen and plasminogen activator inhibitor activity, homocysteine level, ANA screen, dsDNA, and lipoprotein A. Although heterozygosity for MTHFR C677 T was found in both patients, it was not thought clinically relevant in the context of normal homocysteine level [11].

\section{Conclusion}

Our report documents the unique occurrence of transient para-infectious anti-phospholipid antibodies provoked by Mycoplasma infection leading to venous thrombosis and pulmonary embolism in identical female twins. We found no identifiable genetic prothrombotic variables. This does not rule out an underlying unknown genetic factor promoting thrombosis in these identical twins.

\section{Data Availability}

No data were used to support the findings of this study.

\section{Conflicts of Interest}

The authors declare that they have no conflicts of interest.

\section{References}

[1] T. Li, H. Yu, W. Hou, Z. Li, C. Han, and L. Wang, "Evaluation of variation in coagulation among children with mycoplasma pneumoniae pneumonia: a case-control study," Journal of 
International Medical Research, vol. 45, no. 6, pp. 2110-2118, 2017.

[2] B. Medjo, M. Atanaskovic-Markovic, S. Radic, D. Nikolic, M. Lukac, and S. Djukic, "Mycoplasma pneumoniae as a causative agent of community-acquired pneumonia in children: clinical features and laboratory diagnosis," Italian Journal of Pediatrics, vol. 40, no. 1, p. 104, 2014.

[3] Z. Huang, B. Zhang, and B. Cheng, "Mycoplasma pneumoniae pneumonia complicated with pulmonary embolism: a systematic analysis of published case reports," International Journal of Clinical and Experimental Medicine, vol. 9, pp. 11574-11581, 2016.

[4] X. Wu, M. Yang, L. Wu, B. Cheng, and Z. Chen, "Early recognition and management of pulmonary embolism related to mycoplasma pneumoniae infections in children: two case reports and literature review," International Journal of Clinical and Experimental Medicine, vol. 2018, pp. 7510-7515, 2018.

[5] B. Senst, P. Tadi, H. Basit, and A. Jan, "Hypercoagulability," in StatPearls. Treasure Island (FL),StatPearls Publishing LLC, Petersburg, FL, USA, 2020.

[6] N. Abdel-Wahab, M. A. Lopez-Olivo, G. P. Pinto-Patarroyo, and M. E. Suarez-Almazor, "Systematic review of case reports of antiphospholipid syndrome following infection," Lupus, vol. 25, no. 14, pp. 1520-1531, 2016.

[7] N. Abdel-Wahab, S. Talathi, M. A. Lopez-Olivo, and M. E. Suarez-Almazor, "Risk of developing antiphospholipid antibodies following viral infection: a systematic review and meta-analysis," SAGE Journals, vol. 27, pp. 572-583, 2017.

[8] C. Mendoza-Pinto, M. García-Carrasco, and R. Cervera, "Role of infectious diseases in the antiphospholipid syndrome (including its catastrophic variant)," Current Rheumatology Reports, vol. 20, no. 10, p. 62, 2018.

[9] P. Cruz-Tapias, M. Blank, J.-M. Anaya, and Y. Shoenfeld, "Infections and vaccines in the etiology of antiphospholipid syndrome," Current Opinion in Rheumatology, vol. 24, no. 4, pp. 389-393, 2012.

[10] I. W. Uthman and A. E. Gharavi, "Viral infections and antiphospholipid antibodies," Seminars in Arthritis and Rheumatism, vol. 31, no. 4, pp. 256-263, 2002.

[11] S. Moll and E. A. Varga, "Homocysteine and MTHFR mutations," Circulation, vol. 132, no. 1, p. 6, 2015. 